\section{HER GARTER SNAPPED: OLD PROBLEMS, UNIQUE SOLUTIONS}

Delbert E. Philpott

1602 Kamsack Dr. , Sunnyvale, CA 94087

In 1946 Indiana U. purchased an electon microscope sight unseen for $\$ 600$, deciding it was an E.M. on the basis of weight. Seeing Dr. Fischer's ad for an assistant, I wondered what an E.M. was. I dashed upstairs to find his office. Having come directly from the airport where I was a pilot, I was dirty and needed a shave. I planned to come back when I had cleaned up. I put my nose against the door to read his small handwriting and office hours. Out he came. We hung together nose to nose as he asked, "Did you want something?" "Poor time to tell you no," I responded. I got the job in spite of my appearance because, as he told me, I knew photography, could learn the panel on an airplane and wasn't afraid of work. We put the microscope together and it ran! We set up a summer lab course, but he asked me to teach it when he got a sabbatical. Having signed up, I gave myself an A. I was starting at the top. I felt there was a great future if we could just learn to cut sections. The chairman warned me not to make it my career as it was only one instrument, could go away and I wouldn't be able to make a living at it. To show him, I quit with my Master 's Degree and took a job at the U. of IL. Medical School. I learned to cut sections with a tongue depressor (published) and designed an ultramicrotome (published). He was right. At $\$ 300 /$ month, I could barely eat hamburger, but I was showing him.

One day my partner was freezing the specimen block to provide thermal advance. I was on the floor preparing to reach up and slide the knife across the plastic block. The water in our boat had to be horizontal and our crude set-up forced me to be on the floor. When the block froze up, Bill turned the pressure valve on the $\mathrm{CO}_{2}$ tank the wrong way. The copper tube pulled out of the brass block. Whipping like a rubber hose, it caught him in the forehead. He dropped to his knees. I managed to turn off the pressure. Blood streamed down his face. We ran over to the hospital and had his head patched up in record time. We raced back to hide the evidence of our poor engineering, but word had spread. Our small room held everyone, including our petite religious technician (to whom we had never even said darn for fear she would quit) and the chairman. Pointing at us, he demanded to know what had happened. I was speechless. Bill was still in shock, but knew an answer was required. Pointing at our demure technician, he said, "Her garter snapped." That brought down the house, diverted attention from our failure and left the chaiman speechless. By then, someone had fashioned a Purple Heart and an impromptu ceremony took place. Thankfully, our tech saw the humor and even helped pin on the award.

My first publication (inspired by a nude photo class) was called Portrait Shadow Casting and made the cover of the J. of Appl. Physics. We did some nice work and published with Dr. K. Porter. This led me to Woods Hole to work for the Nobel Laureate prize winner, Dr. Albert Szent Gyorgyi whom we called "Prof". He supported the constuction of my $\$ 400$ microtome. I found the afternoon sun would advance the knife if I didn't t pull the window shade. Small movements of the shade adjusted the rate of advance. All I had to do was mark off the window sill in Angstroms to have an ultrafine adjustment. Prof loved it. We demonstrated ultrathin sectioning with a window shade during site tours. Our institute of 15 people was the only group at the $\mathrm{MBL}$ during the winter. Consequently, the big building was poorly heated. On cold days, l'd wear my coat and gloves until the sun's warmth and my Bunsen burners provided enough heat, claiming it avoided static electricity. With no help in the summer, I worked day and night. To get people out at noon so I could eat, I hung a coo-coo clock by the E.M. When it would coo coo at noon, l'd ask the scientist to check if it was indeed twelve o'clock. While they were checking, I'd quickly turn off the 'scope and flip on the lights. I told everyone I could only use that clock as the electric ones would degrade the microscope's resolution.

I worked with Andrew Szent-Gyorgyi to photograph the first protein crystal, light meromysin. We measured the period within a few Angstrom units of that found by $X$-rays a year later. Phil. Person and I were the first to photograph rhibosomes passing through the nuclear pores. remember a lot of caustic remarks about how stupid the idea was, but 6 months later everyone acted as if they had always known. I made a 6 foot wall map of the frog retina for Dr. G. Wald. He would lecture, unrolling it as he went. I managed that by removing the center of a punched out copper grid. Andrew and I had a theory on the "catch mechanism" in clam muscle, but starfish could always open clams. Investigating starfish tube feet, I found adhesive packets moving to the surface - the first bioadhesive working under seawater. This resulted in electron micrographs of it on the covers of Science and A.I.B.S

Prof helped me go back to school at B.U. to get my Ph.D. Just before my oral exams, another picture of mine appeared on the cover of Science. The Dean sent a congratulatory letter and I recall thinking I might pass my orals after all. When the Siemens arrived at B.U., the top of the crate had beautiful German witing. I had it crated and shipped to Dr. K. Porter and sent a letter asking if it was true I could get a subscription to his journal for one boxtop from a Siemens. He sent one cover from his journal with a notation, "One good cover deserves another".

I accepted a professorship at the U. of Colorado Medical School. Two years later, I moved to Mercy Hospital in Denver as Co-Director of the Institute of Medical Problems. Shortly afterwards, I went to NASA where I designed my own E.M. lab and examined lunar soil. I developed a new fixative called Triple Fix for a Mars sample return. It allowed tissues to remain refrigerated indefinitely and was extremely useful when we started flying experiments on Russian spacecraft. I had 5 experiments flown on Russian spacecraft and 6 flown on American spacecraft. The first was on Apollo 17 when we flew 5 pocket mice to the moon. We kept them alive in a small capsule without any connections by enclosing potassium superoxide which reacted with the water from their breathing to produce oxygen. I invented a laser system for tracking the path of the cosmic particles which had traversed the head in order to look for the tracks.

I've had two papers rejected by E.M.S.A., purported to be fakes. I was doing the first E.M. and space flight experiments with the Russians. They had designed a special flight centrifuge which looked different from anything in the West. Unfortunately, the review board had been burned earlier and was super-sensitive. My scoop was considered impossible. New members, being jumpy about fakes, considered the name Philpott to be the final proof it was bogus. My second rejected paper demonstrated regeneration after 1/3 of the salamander's heart was cut off. We used the new scientific name for the salamander, but the committee only knew the old one. We argued and pointed to an accepted abstract backing up our claim. We were finally allowed to present it, but too late to be included in the bulletin.

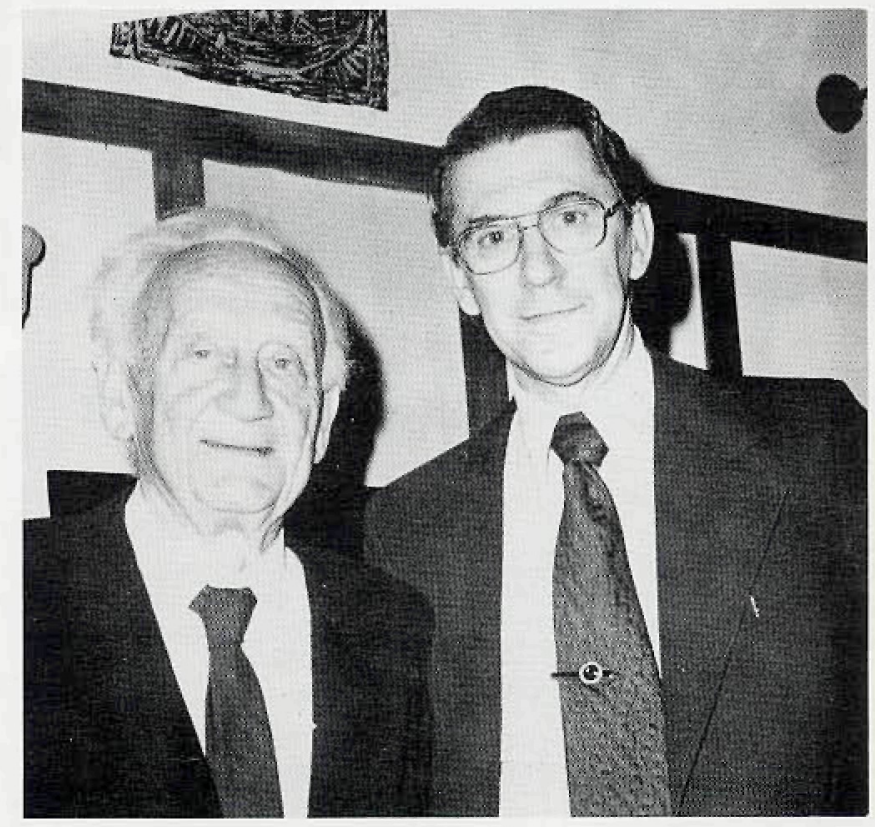

The author with Dr. Albert Szent-Gyorgi (left), Nobel Laureate, Institute for Muscle Research, Woods Hole, MA. 


\section{A Breakthrough in AFM Imaging of Soft Samples.}

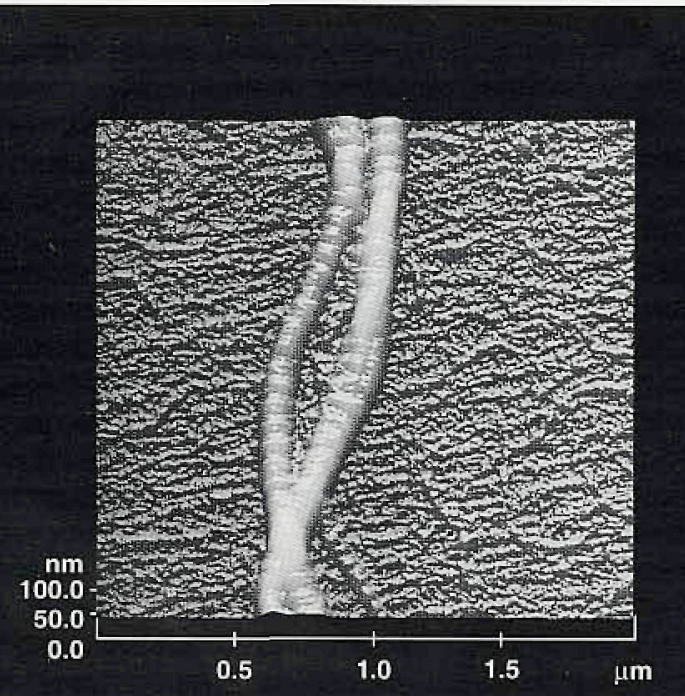

Type I Collagen Scanned in the TappingModeTM (patent pending) using the NanoScope Multimode AFM. Both the $70 \mathrm{~nm}$ bands and the $30 \mathrm{~nm}$ sub-bands are resolved in this uncoated sample. Data: E. Chernoff of Indiana University-Purdue University at Indianapolis, D. Chernoff of Advanced Surface Microscopy, Inc, and K. Kjoller of Digital Instruments.

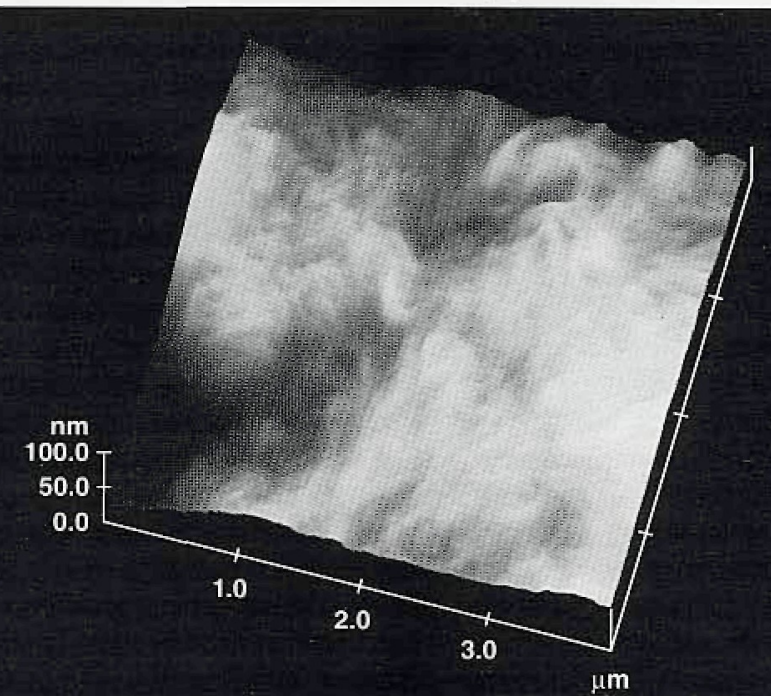

Polyethylene Film Scanned in Air using the TappingMode ${ }^{\mathrm{M}}$ of the NanoScope MultiMode AFM. Now soft, delicate samples like these can be scanned quickly and easily without the use of a fluid cell. This is another example of our commitment to meet our users' needs. Data: C. Boles of Digital Instruments.

\section{The TappingMode ${ }^{\top M}$ of the NanoScope ${ }^{\circledast}$ Multimode Atomic Force Microscope gives you the capability to image soft samples with ultra-high resolution.}

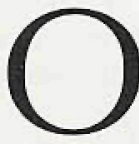

ur exclusive TappingMode ${ }^{\mathrm{TM}}$ AFM makes it easy to image soft, sticky samples without the use of a fluid cell. This newly-discovered scanning probe method allows samples to be measured using very low compressive force-and no lateral force-between the AFM probe tip and the sample. Using the TappingMode, samples such as polymers and biological materials can be imaged in air with ultra-high resolution, and without the tearing and sticking that can occur with standard contactAFMs.
The NanoScope Multimode AFM can also be used as a standard contact AFM, a noncontact AFM, a Magnetic Force Microscope (MFM), a Lateral Force Microscope (LFM), and an Electrochemical AFM-another example of how the NanoScope gives you constantly expanding capabilities.

Call today to discuss your application.

\section{di Digital Instruments}

Santa Barbara, CA •TEL: 805-899-3380 or 800-873-9750 -FAX: 805-899-3392

Japan: Toyo Corp. $\bullet$ TEL: 81-3 (5688) 6800•FAX: 81-3 (5688) 6900 